\title{
As diversas instâncias de formação política dos docentes da rede pública de ensino: aproximações introdutórias
}

\section{Different instances of teachers political formation in the public school system: introductory approaches}

\section{Las diversas instancias de formación política de los maestros de la educación pública: enfoques introductorios}

\author{
Itacir Carlos Valmorbida1 \\ Maurício Roberto da Silva²
}

\section{Resumo}

O texto tem como objetivo apresentar alguns elementos teórico-metodológicos do processo de construção da pesquisa (dissertação de mestrado) que tem por finalidade refletir sobre as potencialidades e os limites de uma proposta de formação política permanente dos docentes. Essa reflexão leva em consideração a articulação das diversas instâncias de formação (pedagógica, político-sindical, político-partidária, acadêmica, etc.) ou "multimilitância", a partir da categoria marxista da "práxis", enquanto elemento teóricometodológico e epistemológico central e unificador dos processos educativos. Tomamos como ponto de partida e inspiração a ideia teórico-prática da "tripla militância", cujo eixo do debate se baseia no exercício de militância sindical, político-pedagógica e acadêmica engendrada na vida cotidiana de um dos autores desse texto. A partir desses elementos empírico-teóricos, o texto se baseia nas contribuições de diversos autores marxistas que tratam da "pedagogia crítica", a partir da "filosofia da práxis", cujos aportes teórico-conceituais, buscam articulações com a ideia dos professores compreendidos enquanto intelectuais orgânicos. As conclusões provisórias apontam para os desafios e necessidade de um processo de formação política de natureza crítico-superadora dos docentes que atuam nas redes públicas de educação, cujo cerne ontológico, epistemológico e político-pedagógico, tem como centralidade a unidade inseparável entre teoria e prática.

Palavras-chave: Docência; Formação Política; Militância; Práxis; Intelectuais orgânicos.

1 Professor da rede pública estadual de Santa Catarina, líder sindical, mestrando em educação da Unochapecó. E-mail: itacircarlos@unochapeco.edu.br. 2 Doutor em Educação. Professor do Programa de Pós-Graduação em Educação da Unochapecó. E-mail: mauransilva@gmail.com. 


\begin{abstract}
The article aims to present some theoretical and methodological elements of the process of research construction (master's dissertation) whose purpose is to reflect on the potentialities and the limits of a proposal of permanent teachers' political formation. This reflection takes into account the articulation of the various instances of formation (pedagogical, political-syndical, political-partisan, academic, etc.) or "multimilitance", from the Marxist category of "praxis" as a theoretical-methodological and epistemological central and unifying element of educational processes. We take as a starting point and inspiration the theoretical-practical idea of "triple militancy", which axis of debate is based on the exercise of unionism, political-pedagogical and academic militancy engendered in the daily life of one of the authors of this work. From these empiricotheoretical elements, the text is based on the contributions of several Marxist authors who deal with "critical pedagogy", based on the "philosophy of praxis", whose theoretical-conceptual contributions seek articulations with the idea of teachers as organic intellectuals. The provisional conclusions point to the challenges and the necessity of a process of political formation of a critical-surpassing nature of the teachers who work in the public education schools, which ontological, epistemological and political-pedagogical center has the inseparable unity between theory and practice .
\end{abstract}

Keywords: Teaching; Political Formation; Militancy; Praxis; Organic intellectuals.

\title{
Resumen
}

El texto tiene como objetivo presentar algunos aspectos teóricos y metodológicos del proceso de construcción de la investigación (tesis de maestria) que tiene como objetivo reflexionar sobre el potencial y los límites de una propuesta de formación política permanente de los maestros. Esta reflexión tiene en cuenta la coordinación de los diversos organismos de formación (pedagógica, político-sindical, político-partidário, académico, etc.) o "multimilitância", a partir de la categoría marxista de la "praxis" como un elemento teórico-metodológico y epistemológico central y unificador de los procesos educativos. Tomamos como punto de partida y inspiración la idea teórica y práctica de la "triple militancia", cuyo eje del debate se basa en el ejercicio de la militancia sindical, político-pedagógica y académica que han surgido en la vida cotidiana de uno de los autores de este artículo. A partir de estos elementos empíricos y teóricos, el texto se basa en las contribuciones de muchos autores marxistas que se ocupan de la "pedagogía crítica", de la "filosofía de la praxis" cuyas contribuciones teórica y conceptual buscan vínculos con la idea de maestros entendidos como intelectuales orgánicos. Las conclusiones provisionales apuntan a los desafíos para el proceso de formación de la política crítico-superadora de los docentes que trabajan en la educación pública, cuyo núcleo ontológico, epistemológico y políticopedagógico es la centralidad de la unidad inseparable entre la teoría y la práctica .

Palabras clave: Docencia; Formación Política; Militancia; Praxis; Intelectuales orgánicos. 


\section{Introdução: Reflexões sobre a delimitação e pertinência do estudo}

O presente texto apresenta de forma sintética o trabalho de uma dissertação de mestrado, que tem como objetivo principal refletir sobre o papel da práxis na formação política dos professores-intelectuais, que atuam nas redes públicas de ensino, em especial no Oeste de Santa Catarina. O trabalho toma como desafio a possibilidade do exercício da militância em algumas instâncias da vida cotidiana dos professores ou, conforme denominamos "multimilitância". A formação política, de acordo com alguns dados da pesquisa de campo, pode ocorrer em diversos tempos e espaços, tais como: sindicato, partido, escola, movimentos sociais, família, igreja e etc. Vale ressaltar que tomamos como ponto de partida e inspiração teórico-metodológica, objetivamente, a ideia teórico-prática da "tripla militância". Essa tríade motivou a construção do problema de pesquisa, cujo eixo se baseia na prática concreta da vida cotidiana do primeiro autor desse texto, através do seu exercício da militância no sindicato dos professores ${ }^{3}$, nas práticas político-pedagógicas das escolas e na produção do conhecimento na pós-graduação da universidade (militância político-científica) ${ }^{4}$.

No limiar das observações realizadas e inquietações sentidas na perspectiva da tripla militância, a hipótese que norteia este texto é a de que a maioria dos professores, que atua no sindicato, carece de uma formação política crítica e radical, calcada em pressupostos epistemológicos e ideológicos mais consistentes, no exercício docente, na elaboração de pesquisa na pós-graduação (militância científica), no sindicato ou em outros temposespaços de formação política da vida cotidiana. Com base nessa hipótese, o teor da pergunta-problema a ser colocada reside em saber: quais os possíveis tempos e espaços de formação política na vida cotidiana dos professores que atuam na rede pública estadual na cidade de Chapecó?

No ponto de vista dos procedimentos de abordagem da realidade (instrumentos de coleta de dados), lançamos mão das primeiras observações (exploratórias), inspiradas em alguns pressupostos da "observação participante"5. Essa opção metodológica se justifica, considerando o fato de que, enquanto intelectuais, estarmos envolvidos de maneira orgânica nas diversas ações e experiências político-pedagógicas. A esse processo teórico-empírico, atribuímos a noção de "tripla militância" que se manifesta nas três instâncias supramencionadas, isto é, no sindicato, escola e na produção do conhecimento (mestrado em educação).

\section{A política e a formação política: em busca dos sentidos e significados para a vida cotidiana dos professores}

Antes mesmo de abordar sobre a questão da formação política dos professores da rede Pública de Ensino, torna-se essencial refletir sobre o que significa política e, fundamentalmente, formação política nas diversas instâncias da vida cotidiana docente. Esse debate é de suma relevância, considerando a polissemia e multidimensionalidade desses conceitos e, consecutivamente, a necessidade do alargamento dessas categorias de análise que abarcam a totalidade do problema de pesquisa.

A política (do grego politiká, uma derivação de polis: aquilo que é do público) é a ciência da governança de um Estado ou Nação e também uma arte de negociação para compatibilizar interesses; é uma atividade orientada ideologicamente para a tomada de decisões de um grupo para alcançar determinados objetivos. Também pode ser definida como sendo o exercício do poder para a resolução de um conflito de interesses. A

3 SINTE - Sindicato dos Trabalhadores em Educação da Rede Pública de Ensino de Santa Catarina.

4 Programa de Pós-Graduação Stricto Sensu/Unochapecó - Mestrado em Educação.

5 A opção pela "observação participante" se dá, considerando que esta implica uma experiência do pesquisador imbricada com a realidade investigada. 0 desafio é não confundir "observação participante" com "participação observante". Em todas as ações o pesquisador tem de possuir clareza quanto à especificidade do seu papel político, seja como pesquisador, seja como militante. Em síntese, trata-se do método de "observação total", também conhecido como "participante total", ou seja, quando o pesquisador se propõe a participar inteiramente "como nativo" em todas as áreas da vida do grupo que está sendo investigadas (MINAYO, 2010, p. 280). 
utilização do termo passou a ser popular no século V a.C., quando Aristóteles desenvolveu a sua obra intitulada precisamente "Política".

Marx e Engels, no capítulo que abre o Manifesto Comunista (1848), intitulado Burgueses e Proletariados, resumem a história da sociedade divididas em classes particulares, "numa palavra, opressores e oprimidos". Em linhas gerais, o capítulo trata da relação entre a burguesia e o proletariado, da evolução dessas duas classes sociais até aquele momento. É neste capítulo do "manifesto" que autores sinalizam que a cada etapa da evolução vencida pela burguesia, esta era acompanhada de um progresso político correspondente, ou seja, "[...] a burguesia, desde o estabelecimento da grande indústria e do mercado mundial, conquistou, finalmente, soberania política no Estado representativo moderno" (MARX; ENGELS, 1999, p. 10). E complementam dizendo que o governo moderno, lê-se, o Estado, não é senão um comitê para gerir os negócios comuns a toda a classe burguesa. A constatação expressa no manifesto de que a política ao longo da história foi sempre se "adaptando", acompanhando o progresso da classe dominante ou ainda, que a história política não faz mais do que refletir as mudanças nas "formas de consciência", é decorrente de um dos princípios centrais do materialismo históricodialético: o modo de produção da vida material (infraestrutura), determina, em geral, o processo social, jurídico, político e intelectual (superestrutura).

Para Marx e Engels, toda luta de classe é uma luta política, é o poder organizado de uma classe para a opressão da outra; já a educação política é arma de luta para a tomada do poder político, já que este é o objetivo (inicial) do proletariado (MARX; ENGELS, 1999, p. 22).

Ainda em relação à política, em Marx (e Engels), duas questões são importantes de serem frisadas: a primeira é a de que a política não se separa do Estado e desse modo, a luta política é a disputa pelo Estado; a segunda é a impossibilidade de a política ser neutra. Isto por que o Estado sempre se coloca a favor da classe dominante, já este foi constituído para representar os interesses da minoria (classe dominante). Nesta perspectiva, a luta política dos trabalhadores (luta de classe) pela tomada do poder político (Estado) é no interesse da maioria (classe oprimida).

Nesta linha de pensamento, a formação política dos docentes tendo por referência as reflexões de Marx (e Engels) acerca de uma teoria e prática, é revolucionária, é práxis. Nesta perspectiva, a luta dos professores por condições de emprego e salário, deve agregar a luta política.

A política pode ser compreendida enquanto práxis social, enquanto "práxis política". Nesse sentido, é uma das modalidades de atividade prática da vida cotidiana do homem, em cujo âmbito "caem os diversos atos orientados para a sua transformação como ser social e, por isso, destinados a mudar as relações econômicas, políticas e sociais" (grifos nossos). A práxis política, "[...] é uma atividade que toma como objeto, não o individuo isolado da realidade, mas, essencialmente o coletivo, as classes sociais e a sociedade inteira" (SANCHEZ VASQUEZ, 2007, p. 230).

Considerando que estamos problematizando o conceito de política, relacionado à práxis dos professores e, consequentemente, a formação política destes nas diversas instâncias da vida cotidiana, vale ressaltar que, num sentido mais restrito a práxis social é a atividade de grupos ou classes sociais que leva a transformar a organização e a direção da sociedade, ou a realizar certas mudanças mediante a atividade do Estado. Portanto, essa forma de práxis se constitui numa "atividade política". Pelo exposto, esse parece ser o desafio dos professores, ou seja, numa sociedade capitalista, dividida em classes antagônicas, compreender a política como a luta de classes pelo poder e a estruturação da sociedade, de acordo com as demandas, interesses e fins correspondentes às lutas, nesse caso, dos trabalhadores da educação (SANCHEZ VASQUEZ, 2007, p. 231).

Ao fim e ao cabo, é preciso reconhecer que a práxis política, enquanto atividade transformadora, pode alcançar a sua forma mais alta na práxis revolucionária como etapa superior da transformação prática da sociedade. Com efeito, na sociedade dividida em classes antagônicas, a atividade revolucionária pode significar a mudança radical das bases econômicas e sociais, no qual se assenta o proletariado (trabalhadores 
da educação). Essa mudança deve ser pensada de forma consciente, organizada e dirigida, que pressupõe a existência de partidos que possam elevar a consciência de classe, para que possam traçar claramente os objetivos das lutas, suas estratégias e suas táticas, articuladas com a "atividade teórica". Vale ressaltar que [...] a atividade teórica por si só não mostra os traços que consideramos privativos da práxis. Sendo assim, "[...] não devemos colocá-la no mesmo plano que as formas da atividade prática, pela simples razão de que ela não é uma forma de práxis" (SANCHEZ VASQUEZ, 2007, p. 231), visando assim à organização política e ideológica e político-pedagógica em busca de uma educação efetivamente pública e de qualidade.

Postas algumas ideias sobre o conceito de política, torna-se importante trazer para o texto o entendimento sobre "formação política", pois, afinal, essa é a centralidade do problema de pesquisa. Assim, para responder a pergunta-problema, cujo cerne é a questão da formação política dos docentes nas diversas instâncias da vida cotidiana (sindicato, escola, partido, família, formação acadêmica stricto senso, igreja e etc.), necessário se faz debater sobre o significado do termo "formação política" à luz do que já foi anteriormente discutido sobre práxis política.

\section{A práxis e a formação política na docência}

A noção de práxis a se adotar nesta reflexão em torno das potencialidades e limites de um processo de formação política permanente para os docentes, articulando- se elementos das diversas militâncias e mais especificamente, da tripla militância, tem como referência as contribuições do filósofo hispânico-mexicano Adolfo Sánchez Vázquez. Neste sentido, vê-se a necessidade de distinguir a atividade de práxis. Embora de modo pouco aprofundado, em concordância com o referido autor: "Toda práxis é atividade, mas nem toda atividade é práxis" (VÁSQUEZ, 2007, p. 219). Trata-se, portanto, de uma forma específica de atividade, a qual, em sentido amplo, refere-se ao ato ou conjunto de atos realizado por um agente ativo seja físico, biológico ou humano que acarreta certa transformação, (produto) em diversos níveis. Enquanto a práxis é entendida como a ação real, objetiva, transformadora e consciente sobre uma dada realidade natural ou humana. Portanto, não é atividade puramente material, tampouco puramente espiritual; a noção de práxis está no cerne da compreensão da relação entre teoria e prática e, assim, a superação da falsa dicotomia entre os aspectos objetivos e subjetivos.

A mencionada noção de práxis traz em seu bojo uma das premissas centrais presente na tradição marxista, ou seja, a perspectiva de que só faz sentido refletir, pensar e analisar a realidade com o objetivo de transformála. No entanto, para transformar a realidade é preciso atuar em todas as instâncias sociais, relacionadas aqui como frentes de luta, a saber: sindicato, partido, escola, na produção do conhecimento na academia e outros, munido de esperança. Os sentidos tanto para as teorizações como para as práticas estão na produção de possibilidades esperança para engendrar transformações sociais.

\section{Apontamentos introdutórios sobre a práxis e os desafios da formação política nas diversas instâncias da vida cotidiana e para além da "tripla militância"}

Para evitar confusões teórico-conceituais e teórico-metodológicas, urge pensar não apenas numa pedagogia "crítica", porém numa educação para além da lógica do mercado (APLLE, 2005), em suma, para além do capital (MÉSZÁROS, 2014). Vale ressaltar que, neste aspecto, é preciso ter clareza da necessidade da compreensão mais robusta sobre a pedagogia crítica e a educação crítica, a qual, cada vez mais, deve basearse na importância das múltiplas dinâmicas que sustentam as relações de exploração e dominação (APPLE et

6 Na obra Para além da lógica do mercado: compreendendo e opondo-se ao neoliberalismo, RJ: DP\&A, 2005, Michael W. Apple discute 0 impacto das macropolíticas neoliberais sobre a educação, suas influências sobre o cotidiano das escolas, como, por exemplo, a culpabilização da classe docente pelo "fracasso" da educação. 
al, 2011, p. 14), principalmente, no limiar da acumulação capitalista neoliberal. Portanto, o desafio é, diante da dimensão assumida pelo capital, enquanto modo histórico e sistema orgânico que controla a reprodução do metabolismo social, pensar a educação na assertiva de Mészáros,7 "como desenvolvimento contínuo da consciência socialista", processo permanente que contribui para a transformação revolucionária de todas as dimensões da vida social (MÉSZÁROS, 2001, p. 298).

Esse processo, para além do capital, tem como referência o ser humano. Os autores mencionados buscam, com suas reflexões críticas, contribuir para a construção de um cenário de esperança, de possibilidades; uma utopia crítica fundamentada na dialética entre teoria (crítica) e prática (revolucionária). Isso é imprescindível para o processo de formação política dos professores, na perspectiva de formação de intelectuais críticos e transformadores, considerando o empobrecimento atual da formação política docente da formação inicial à formação continuada e a carência de experiências concretas em termos de pedagogia crítica.

Nossa ideia é contribuir com as reflexões críticas e de relevância pessoal, acadêmica e social, sobre o processo de formação política dos professores tomando como eixo teórico-metodológico algumas categorias do materialismo histórico-dialético. Assim, para que haja forma militante de atuar, é preciso uma formação política, calcada no ideário da práxis revolucionária que, por sua vez, exige uma reflexão sobre a consciência de classe e, por conseguinte, na organização política. Em síntese, são esses os elementos teórico-práticos que buscam oferecer elementos teórico-conceituais e teórico-empíricos, visando construir uma noção ampliada e dinâmica da ideia de tripla militância e multimilitância.

Quando está em pauta a formação política do professor das redes públicas de ensino, os quais estão produzindo pesquisas em cursos de pós-graduação, a militância também poderia ser compreendida como a construção de um processo reflexivo e crítico ao capital. O desafio, neste aspecto, consiste em articular o conhecimento teórico-científico com os problemas concretos ou "concreto pensado" trazidos do cotidiano do trabalho pedagógico, do trabalho científico e da luta política sindical. Esses são os desafios e elementos que se articulam e constituem argumentos objetivos para discutir um processo de formação política permanente para os professores da rede pública.

Nessa mesma direção, a consciência de classe para quem atua nas escolas apresenta-se ainda de modo muito frágil e volátil. Isso se dá, possivelmente, devido às condições objetivas de trabalho dos docentes, na maioria das vezes imersos no mundo da precarização do trabalho com salários aviltantes, formação continuada inexistente ou com conteúdos desarticulados das problemáticas da temporalidade e da lógica neoliberal. Sendo assim, tratar a respeito da "multimilitância enquanto práxis revolucionária" no cotidiano da docência nas escolas carece da realização de estudos mais específicos sobre a questão.

\section{O desafio da formação política como estratégia de "resistência ativa", a partir da educação crítica e da práxis}

No materialismo histórico-dialético, a práxis é uma categoria central que traz em seus pressupostos a luta e a militância, no sentido de superação das contradições do capitalismo. Nesse caso, a multimilitância dos professores, enquanto elemento teórico-prático essencial de formação política, quer seja nas escolas, no partido, no sindicato, nas universidades entre outros, traz consigo a ideia de "resistência ativa" como tática de luta e resistência, em prol dos interesses e demandas materiais e imateriais da classe trabalhadora.

A conceito de resistência ativa, enquanto atividade teórico-prática ou forma de luta consciente encontra fundamentação na tradição teórica marxista. Para Saviani, a resistência ativa reflete uma estratégia ou uma arma de luta contra as políticas públicas educacionais de caráter neoliberal que predominam no cenário

7 As obras tomadas aqui como referência foram: A educação para além do Capital. São Paulo: Boitempo, 2014; 0 desafio e 0 fardo do tempo histórico. São Paulo: Boitempo, 2011. 
atual (SAVIANI, 2011, p.142). Trata-se de uma organização coletiva e de caráter propositivo; uma forma de resistência que procura ultrapassar o âmbito do direito de apenas discordar (resistência passiva). Nesses termos, a resistência ativa segundo o referido pesquisador, representa a efetiva participação dos trabalhadores para resistirem "[...] à tendência dominante, mas formulando e apresentando alternativa [...]" (Idem). Ou seja, a resistência ativa, que tem raízes na pedagogia crítica, representa uma possibilidade de reverter à situação, pelo conteúdo e pela forma de mobilização.

A prática da resistência ativa no exercício da multimilitância apresenta-se como possibilidade de materialização da práxis (criativa e imitativa), ou seja, a práxis expressada concretamente no desenvolvimento das atividades da docência, da política sindical, partidária, da pesquisa acadêmica e etc. Esse exercício representa, acima de tudo, uma mudança de linguagem ou de discurso: da crítica - inoperante - para a possibilidade da crítica superadora (esperança). Essa mudança, no entanto, depende inextricavelmente da forma como se concebe o homem, o mundo e a sociedade tomando um eixo de intervenção crítica na realidade, a partir do engajamento teórico-prático e político.

O argumento da práxis criativa como possibilidade de esperança e utopia dialética tem como pressuposto a recuperação da natureza do trabalho docente, do trabalho intelectual. Isso se impõe como uma necessita políticopedagógica, em face de uma forte tendência, embora não seja recente, ${ }^{8}$ que concebe o trabalho docente cada vez mais técnico com a padronização do conhecimento, que facilita seu gerenciamento e controle. A cultura do gerenciamento ou o que Giroux chama de pedagogias gerenciais, ${ }^{9}$ acaba por inibir e desvalorizar o trabalho intelectual crítico (GIROUX, 1988, p. 17). A cultura do gerenciamento na educação refere-se a uma tendência que tem contribuído para acentuar uma característica histórica da educação, a separação entre concepção e execução, ou seja, entre os que pensam a educação e os que a colocam em prática. Em resumo, representa um processo alienante.

A práxis exercida nas diversas instâncias de formação política, poderá se configurar como possibilidade para os professores assumirem, na teoria e na prática, a função política que devem desempenhar. Trata-se dos professores enquanto intelectuais transformadores (GIROUX, 1988, p. 31; GIROUX, 1997, p. 186); intelectuais movidos pelos pressupostos teórico-práticos da consciência de classe e, dialeticamente, pela práxis revolucionária; movidos pela crítica e para as necessárias transformações sociais na educação.

Para Giroux, "as instituições de treinamento de professores e as escolas públicas têm, historicamente, se omitido em seu papel de educar os docentes como intelectuais" (GIROUX, 1988, p. 17). As entidades de classe (sindicatos de professores) têm contribuído pouco para este propósito. Esta instituição, em articulação com a escola e universidade, enverga um grande potencial para a formação de intelectuais que vão atuar dentro e fora da sala de aula.

O professor, como intelectual, não deve se abstrair do caráter político do que ele faz ou deixa de fazer, ou seja, deve pensar a realidade politicamente. Porém, pensar politicamente é, sob a ótica de Florestan Fernandes (2010), alguma coisa que não se aprende fora da prática. Nessa premissa, corrobora-se com a posição de Fernandes de que a atividade militante é uma ação que educa (FERNANDES, 2010, p. 129). O professor, por viver em constante tensão política com a realidade, só pode atuar sobre esta na medida em que se consegue percebê-la politicamente, e desse modo, se almeja por mudança, esta precisa ser realizada nos dois níveis, ou seja, dentro e fora da escola. É por esse motivo que o referido autor reitera a fusão de papéis: professoreducador e cidadão (FERNANDES, 2010, p. 128).

8 De acordo com Giroux (1988), nos Estados Unidos essa tendência, a qual chamou de "racionalidade tecnocrática", surge na educação no início do século XX e se acentua na década de 1980.

9 Pedagogias que reduzem a questão central da aprendizagem ao problema do gerenciamento ou a alocação dos recursos humanos (professores e alunos) e materiais. 


\section{Considerações provisórias: desafios da formação política nas diversas instâncias da vida cotidiana para os professores-intelectuais que atuam nas redes públicas de ensino}

Enquanto conclusão provisória, apontamos para a necessidade de um processo de formação política de natureza crítico-superadora dos docentes que atuam nas redes públicas de educação, cujo cerne ontológico, epistemológico e político pedagógico, a partir da unidade inseparável entre teoria e prática, enfim, da práxis. É essa unidade que consubstancia a formação política nas diversas facetas do cotidiano das práticas políticas e educativas (multimilitância). Com efeito, refletir sobre o alargamento e aprofundamento do processo de formação política dos docentes e pensar numa efetiva práxis política, representa um desafio que requer uma proposição política que ultrapasse a lógica do capital. Para tanto, a formação permanente de professores, tem que pautar-se na construção de compromissos éticopolíticos, no sentido de possibilitar uma radical transformação do conceito e prática dos processos de formação política na docência. Esse é um desafio que deve levar em consideração a agenda de lutas acirradas nas greves engendradas pelos sindicatos de professores, que requerem embates permanentes entre capital e trabalho, e que por sua vez, visam o combate às políticas educacionais neoliberais e por uma educação pública e de qualidade.

Em suma, é preciso "criar condições para a possiblidade de ação revolucionária onde a luta coletiva se torne uma forma de descobrir novas aberturas através das quais se podem gerar perspectivas, construir e mobilizar estratégias com o objetivo da emancipação e empowerment popular" (McLAREN, 2007, p. 58). Na verdade, trata-se de um exercício de continuidade da luta pela democracia substantiva no Brasil, principalmente, num momento histórico em que a democracia se encontra ameaçada pelo movimento conservador, reacionário, de extrema direita e protofascista que está comandando a pauta política, conforme anuncia Marilena Chauí no seu livro Cultura e democracia: o discurso competente e outras falas (2011). Há, neste sentido, uma enorme dificuldade para instaurar e consolidar uma instituição de uma democracia substantiva, numa sociedade vertical, oligárquica, conservadora hierarquizada e estruturada na violência estrutural. Há, nesta direção, sob a égide do neoliberalismo, o encolhimento do espaço público e o alargamento do espaço privado, ou o que ficou conhecido como privatização.

Some-se a isso, o processo de encolhimento da democracia, mediado pelo conservadorismo da classe média urbana e pela presença avassaladora do fundamentalismo religioso das igrejas evangélicas. Na verdade, trata-se de uma insólita (mas não casual) articulação do autoritarismo brasileiro com a acumulação capitalista neoliberal, bloqueando a criação da cidadania. É claro, que tudo isso acontece, mas não sem a força da resistência ativa, engendrada pela luta de classes realizada pelos sindicatos e movimentos sociais mais revolucionários, os quais tem como desafio a formação política dos seus filiados e da população em geral, problematizar com críticas radicais, as relações entre ética e política e os problemas da moralização da política como substituto para a moralidade institucional ou pública (CHAUÍ, 2011, p. 12).

Ao fim e ao cabo, os desafios que se apresentam são incomensuráveis, quando está em jogo a formação política crítica, radical e superadoradora dos trabalhadores da educação. São desafios que se impõe, sobretudo, em tempos de "golpe" à democracia e suas repercussões para a "cidadania em construção". Trata-se de processo de regressão civilizatória que pode ser chamado também de "modernização conservadora", uma vez que, de forma violenta, busca articular "as forças sócias neoliberais, neoconservadores, conservadores religiosos autoritários e populistas" 10

Para enfrentar tudo esse caráter da inversão dos sentidos e significados da política e da formação política, forjada no limiar do neoliberalismo e suas ameaças de destruição dos direitos de todos os trabalhadores em geral e, particularmente, dos professores só nos resta propor refletir sobre os versos de Bertold Brecht a seguir:

10 Estamos nos referindo ao recente episódio de impeachment da presidenta Dilma Rousseff, protagonizado sob a batuta da mídia burguesa, pela (in) justiça social e política do STF, Câmara dos Deputados e Senado que, de modo bizarro e vergonhoso, assaltaram a democracia, rasgando as leis previstas na Constituição Federal. Le Monde Diplomatique. Editorial: Dançando conforme a música. Ano 9, no. 100, 2015; "Carta capital”, 27 de abril de 2016, Ano XXII, no. 898 
Hay hombres que luchan um día y son buenos.

Hay otros que luchan um año y son mejores. Hay quienes luchan muchos años, y son muy buenos. Pero los hay que luchan toda la vida: esos son los imprescindibles.

Bertolt Brecht ${ }^{11}$

\section{Referências}

APPLE, M.; AU, W.; GANDIN, L. A. O mapeamento da educação crítica. In: Educação Crítica: análise internacional. Porto Alegre: Artmed, 2011.

APPLE, M. W. Para além da lógica do mercado: compreendendo e opondo-se ao neoliberalismo. Rio de Janeiro: DP\&A, 2005.

BRECHT, B. Poemas - 1913 - 1956. Ed. Brasiliense, 1986.

CHAUÍ, M. Cultura e Democracia: o discurso competente e outras falas. 13. ed. São Paulo: Cortez, 2011,

GIROUX, H. Os Professores como Intelectuais: Rumo a uma pedagogia crítica da aprendizagem. Porto Alegre: Artes Médicas, 1997.

Escola Crítica e Política Cultural. 2.ed. São Paulo: Cortez/Autores Associados, 1988.

MACLAREN, P. Pedagogia Crítica Contra o Império. Portugal: Pedago, 2007.

MARX, K.; ENGELS, F. O manifesto comunista (1948). E-book. eBookBrasil.com - 1999. Disponível em: http:// www.ebooksbrasil.or/adobeeboow/manifestocomunista.pdf.

MÉSZÁROS, I. A educação para além do capital. 2. ed. São Paulo: Boitempo, 2014.

O desafio e o fardo do tempo histórico. São Paulo: Boitempo, 2011.

MINAYO, M. C. S. O desafio do conhecimento: pesquisa qualitativa em saúde. 12 ed. São Paulo: Hucitec, 2010.

OLIVEIRA, M. M. Florestan Fernandes. Recife: Massangana, 2010.

SÁNCHEZ VÁZQUEZ, A. Filosofia da práxis. São Paulo: Expressão Popular, 2007.

SAVIANI, D. Dermeval Saviani: pesquisador, professor e educador. (Org.) Diana Gonçalves Vidal. Belo Horizonte: Autêntica/Autores Associados, 2011.

Recebido em Maio de 2016 | Aprovado em Junho de 2016

11 Eugen Berthold Friedrich Brecht (1898-1956) foi um dramaturgo e poeta alemão, é reconhecido por colocar sua obra a serviço das questões sociais. 